\title{
Beginning to Integrate Care for Diabetes and Depression
}

Ann Fam Med 2012;10:iii. doi:10.1370/afm.1355.

$\mathrm{T}$ The Annals of Family Medicine encourages readers to develop a learning community of those seeking to improve health care and health through enhanced primary care. You can participate by conducting a RADICAL journal club and sharing the results of your discussions in the Annals online discussion for the featured articles. RADICAL is an acronym for Read, Ask, Discuss, Inquire, Collaborate, Act, and Learn. The word radical also indicates the need to engage diverse participants in thinking critically about important issues affecting primary care and then acting on those discussions. ${ }^{1}$

\section{HOW IT WORKS}

In each issue, the Annals selects an article or articles and provides discussion tips and questions. We encourage you to take a RADICAL approach to these materials and to post a summary of your conversation in our online discussion. (Open the article online and click on "TRACK Comments: Submit a response.") You can find discussion questions and more information online Ant at: http://www.AnnFamMed.org/AJC/.

\section{CURRENT ELECTION}

\section{Article for Discussion}

Bogner HR, Morales KH, de Vries HF, Cappola AR. Integrated management of type 2 diabetes mellitus and depression to improve medication adherence: a randomized controlled trial. Ann Fam Med. 2012;10(1):15-22.

\section{Discussion Tips}

Care of people with multiple medical conditions is the norm in family practice. ${ }^{2}$ Yet, how to integrate, personalize, and prioritize care of multimorbid conditions often is relegated to the art of medicine. ${ }^{3}$ This study moves beyond a one-disease-at-a-time approach to support the higher order integrative function of primary care. ${ }^{4}$

\section{Discussion Questions}

- What questions are asked by this study, and why do they matter?
- How does this study advance beyond previous research and clinical practice on this topic?

- How strong is the study design for answering the questions?

- Does the registration of the study at http://clinicaltrials.gov increase your confidence in the findings?

- To what degree can the findings be accounted for by:

1. How patients were selected, excluded, or lost to follow-up?

2. How the main variables were measured?

3. Confounding (false attribution of causality because 2 variables discovered to be associated actually are associated with a 3rd factor)?

4. Chance? (Optional statistical nerd question: How, other than dichotomizing, might the highly skewed adherence data have been handled?)

5 . How the findings were interpreted?

-What are the main study findings?

- How comparable is the study sample to similar patients in your practice? What is your judgment about the transportability of the findings?

- What contextual factors are important for interpreting the findings?

- What else do you need to know to optimize care for people with both diabetes and depression?

- How might this study change your practice? Policy? Education? Research?

- Who is affected by the findings, and how might they be engaged in interpreting or using the findings?

- What are the next steps in interpreting or applying the findings?

-What researchable questions remain?

\section{References}

1. Stange KC, Miller WL, McLellan LA, et al. Annals Journal Club: It's time to get RADICAL. Ann Fam Med. 2006;4(3):196-197. http:// annfammed.org/cgi/content/full/4/3/196.

2. Fortin M, Bravo G, Hudon C, Vanasse A, Lapointe L. Prevalence of multimorbidity among adults seen in family practice. Ann Fam Med. 2005;3(3):223-228.

3. Stange KC. The generalist approach. Ann Fam Med. 2009;7(3):198-203.

4. Stange KC. A science of connectedness. Ann Fam Med. 2009;7(5): 387-395. 